\section{Hermafroditismo Verdadeiro: Experiência Com 36 Casos}

\section{RESUMO}

Objetivo: Apresentar dados de pacientes com Hermafroditismo Verdadeiro (HV) diagnosticados e acompanhados em dois serviços de referência para o diagnóstico e tratamento de anomalias da diferenciação sexual no Estado de São Paulo. Casuística: Foi composta de 26 HV acompanhados no Instituto da Criança - USP entre 1975 e 2004 e outros 10 casos acompanhados no GIEDDS - UNICAMP entre 1989 e 2004. Métodos: Foram analisados retrospectivamente os dados clínicos e anatomopatológicos, bem como a definição do sexo de criação. Resultados: A queixa prevalente foi ambigüidade genital (34 em 36 casos) e a mediana da idade à primeira consulta foi de 20 meses. A opção para o sexo feminino foi tomada em $55,6 \%$ dos pacientes. Prevaleceu o cariótipo 46,XX (47,2\%) seguido por mosaicos $(27,8 \%)$. 0 SRY foi negativo em todos os pacientes com cariótipo 46,XX e a gônada mais freqüentemente encontrada foi ovotéstis (OT-47\%), seguida de ovário (OV-27\%) e testículo (TT - 24\%). As associações mais freqüentes foram OV + TT (30,5\%), OT + OT (22,2\%) e OT + OV (22,2\%). A opção do sexo de criação independeu do cariótipo, do tamanho do falo e da dosagem sérica de testosterona, mas foi influenciada pelo posicionamento do meato uretral, que, quando não era perineal (11 casos), levou todos à opção masculina. Em cinco pacientes, todas $46, \mathrm{XX} \mathrm{com}$ opção para sexo feminino, pôde-se preservar a porção ovariana do ovotéstis. Conclusōes: O HV continua a desafiar clínicos e investigadores pelo fato de, na maioria dos casos, o cariótipo ser 46,XX, o SRY estar ausente e, ainda assim, haver o desenvolvimento de tecidos ovariano e testicular. A opção preferencial é para o sexo feminino, e a tentativa de preservar o componente ovariano do ovotéstis pode permitir puberdade espontânea e fertilidade. (Arq Bras Endocrinol Metab 2005;49/1:71-78)

Descritores: Hermafroditismo verdadeiro; Testículo; Ovário; Ovotéstis; Ambigüidade genital; Intersexo; SRY

\section{ABSTRACT}

True Hermaphroditism: Experience With 36 Patients.

Aim: to show data on true hermaphrodites (TH) followed in two reference centers in the state of São Paulo. Patients: Twenty-six TH patients have been followed from 1975 to 2004 in the Pediatric Endocrinology Unit, São Paulo University Medical School, and the other 10 patients from 1989 to 2004 in the GIEDDS - UNICAMP. Methods: Clinical and pathological data were retrospectively analyzed, as well as the decision about the sex of rearing. Results: genital ambiguity was the most frequent complaint (34/36 cases) and the age at the first appointment was 20 mo (median). In $55.6 \%$ of the patients the female option was taken. The most frequent karyotype was $46, \mathrm{XX}(47.2 \%)$, followed by mosaicisms (27.8\%). SRY was negative in all 46,XX TH patients and the prevalent gonad was ovotestis (OT-47\%), followed by ovary (OV-27\%) and testis (TT-24\%). The prevalent gonadal associations were OV+T (30.5\%), OT+OT (22.2\%) and $\mathrm{OT}+\mathrm{OV}(22.2 \%)$. The decision about the sex of rearing did not depend on

\section{artigo original}

\author{
Durval Damiani \\ Dulce Rondina Guedes \\ Daniel Damiani \\ Nuvarte Setian \\ Andréa T. Maciel-Guerva \\ Maricilda Palandi de Mello \\ Gil Guerra-Júnior
}

Unidade de Endocrinologia

Pediátrica (Durval D, DRG \& NS),

Instituto da Criança, Faculdade de

Medicina da Universidade de São

Paulo (ICr-FMUSP);

Universidade de Santo Amaro

(Daniel D) (UNISA), São Paulo;e

Grupo Interdisciplinar de Estudos da

Determinação e Diferenciação do Sexo (ATM-G, MPM \& GG-J) da

Faculdade de Ciências Médicas da

Universidade de Campinas (GIED-

DS - FCM - UNICAMP),

Campinas, SP.

Recebido em 07/09/04 Aceito em 14/11/04 
karyotype, phallus size, and testosterone levels. However, the location of the urethral meatus was taken into account in this decision: 20 (80\%) patients out of the 25 with perineal urethra were reared as females while all 11 with "non-perineal" urethra were reared as males. In five $46, \mathrm{XX}$ patients reared as females it was possible to maintain the ovarian portion of the ovotestis. Conclusions: TH keeps on defying clinicians and investigators since most patients are $46, X X$ and SRY-negative, and yet they are able to develop testicular and ovarian tissues. The female sex of rearing seems to be the most adequate, and it is important to try to preserve, in these cases, the ovarian portion of the ovotestis, allowing the patient to have normal puberty and fertility. (Arq Bras Endocrinol Metab 2005;49/1:71-78)

Keywords: True hermaphroditism; Testis; Ovary; Ovotestis; Genital ambiguity; Intersex; SRY

O Hermafroditismo Verdadeiro (HV) pode cursar ou não com genitália ambígua e seu diagnóstico exige a constatação histológica de tecido ovariano (folículos ou corpora albicantia) e testicular (túbulos seminíferos, espermatogônias, espermatozóides); a simples presença de estroma fibroso não caracteriza ovário, assim como o encontro somente de células de Leydig não configura testículo (1).

$\mathrm{Na}$ maior parte do mundo, o HV é uma causa rara de ambigüidade genital, variando de 2 a $10 \%$ (2). A incidência varia, sendo mais alta na África do Sul, com 17 casos por 100 milhões de habitantes, correspondendo a quase $50 \%$ dos casos de intersexo; poucos casos publicados são originários da Ásia e da América do Sul (3).

Desde a descrição do primeiro caso por Salen em 1899, pouco mais de 700 casos já foram publicados na literatura médica $(2,4)$. No entanto, é possível que muitos não sejam diagnosticados, particularmente quando a constituição cromossômica é $46, \mathrm{XY}$, já que em pseudo-hermafroditas masculinos não se realiza sistematicamente o estudo histológico das gônadas $(5,6)$.

A gônada mais freqüentemente encontrada é o ovotéstis, seguida de ovário e testículo, sendo mais comum que as gônadas com predomínio de tecido testicular ocorram no lado direito e aquelas com predomínio ovariano no lado esquerdo. A associação gonadal mais descrita na literatura é ovotéstis com ovário, seguida de dois ovotéstis e de ovário com testículo (2).

A maioria dos pacientes apresenta constituição cromossômica 46,XX (60\% dos casos), e em apenas 10\% o cariótipo é homogêneo 46,XY ou há aberração estrutural do cromossomo $\mathrm{Y}$; mosaicismos variados ou quimeras $(46, \mathrm{XX} / 46, \mathrm{XY})$ respondem pelos restantes
$30 \%$ dos casos (2). A grande questão pendente referese a como é possível haver diferenciação testicular em um indivíduo com cariótipo 46,XX e diferenciação ovariana em um indivíduo 46,XY (7).

Com a caracterização do gene $S R \Upsilon$ (Sex-determining Region on the $\Upsilon$ chromosome) como o fator determinante de testículo, acreditou-se que a explicação viria da demonstração da presença desse gene nos indivíduos 46,XX e de alguma alteração em sua função nos casos com cariótipo 46,XY. No entanto, 90\% dos HV 46,XX não apresentam o gene $S R Y$ e são raríssimas as mutações desse gene levando a HV (5,6,8-11).

Este estudo teve por objetivo apresentar os dados clínicos, anátomo-patológicos e laboratoriais, bem como a opção do sexo de criação de 36 pacientes diagnosticados como HV, acompanhados no Instituto da Criança da Faculdade de Medicina da Universidade de São Paulo (ICr - FMUSP) e no Grupo Interdisciplinar de Estudos da Determinação e Diferenciação do Sexo da Faculdade de Ciências Médicas da Universidade de Campinas (GIEDDS - FCM - UNICAMP).

\section{CASUÍSTICA E MÉTOdOS}

Foram avaliados retrospectivamente os dados de 36 pacientes com $\mathrm{HV}$, todos caracterizados histologicamente pela presença de tecido testicular e ovariano, sendo 26 acompanhados no ICr - FMUSP entre 1975 a $2004(5,12)$, e 10 no GIEDDS - FCM - UNICAMP entre 1989 e 2004 (6).

Os dados foram obtidos a partir dos prontuários dos pacientes, e consistiram de:

1. idade na primeira consulta em meses;

2. sexo definido na primeira consulta: feminino, masculino ou indeterminado;

3. sexo de criação final: feminino ou masculino;

4. comprimento do falo em $\mathrm{cm}$, transformado a seguir em desvio-padrão de acordo com os dados de Lee e cols., 1980 (13); com isso, os pacientes foram divididos em 3 grupos: $\leq-2,5$ DP, entre -2,5 e -1 DP, e $\geq-1$ DP;

5. localização da abertura uretral: balânica, peniana, penoescrotal ou perineal;

6. cariótipo a partir de linfócitos de sangue periférico utilizando técnicas convencionais de bandamento: 46,XX, 46,XY ou aberração estrutural de Y sem mosaicismo, e mosaicismos ou quimerismos;

7. estudo molecular do SRY (a partir de DNA genômico, extraído de leucócitos periféricos, após amplificação por PCR): realizado nos 
casos de cariótipo 46,XX; nos casos 46,XY, seqüenciamento do gene;

8. dosagens de testosterona total: basal e, quando necessário, após estímulo com gonadotrofina coriônica humana, sendo considerada resposta normal valores maiores ou iguais a $150 \mathrm{ng} / \mathrm{dL}$ (7); os resultados obtidos foram agrupados em: $\geq 150$, entre 100 e $150, \leq$ 100, e não dosada;

9. tecido gonadal (ovário, testículo, ovotéstis, gônada disgenética ou ausência de tecido gonadal) e sua lateralidade; a partir dos dados obtidos, os pacientes foram divididos nos seguintes grupos: ovotéstis + ovotéstis, ovotéstis + ovário, ovotéstis + testículo, ovotéstis + gônada disgenética, ovotéstis + gônada ausente, e ovário + testículo.

Os dados foram arquivados em SPSS versão 11.0 e analisados de forma descritiva; quando necessário, foram calculadas a média, mediana e desvio-padrão (DP). Foi realizado o teste do qui-quadrado para os grupos de sexo final de criação contra cariótipo, tamanho do falo, tecido gonadal e testosterona total; e para os grupos de tecido gonadal contra testosterona total e cariótipo. Foram considerados significativos valores de $\mathrm{p}<0,05$.

\section{RESULTADOS}

Os casos de 1 a 26 foram os diagnosticados e acompanhados no ICr - FMUSP $(5,12)$ e os de 27 a 36 no GIEDDS - FCM - UNICAMP (6).

Os pacientes foram avaliados clinicamente, chegando ao Serviço, na sua maioria, com queixa de ambigüidade genital. Apenas um dos pacientes (caso 22) veio em idade puberal devido à ginecomastia bilateral, enquanto que uma criança de 3 meses de idade veio devido à hipoglicemia (Síndrome de Beckwith-Wiedemann), ocasião em que foi constatada também a ambigüidade genital (caso 24).

A média de idade na primeira consulta foi de 4 anos com DP de 5,1 anos, variando de 10 dias a 19 anos e 11 meses, com mediana de 1 ano e 8 meses. Apenas 6 pacientes $(16,6 \%)$ vieram antes de 1 mês de vida; e $23(63,8 \%)$ antes de 2 anos de idade (tabela 1).

$\mathrm{Na}$ primeira consulta, o sexo era masculino em $22(61,2 \%)$, feminino em $7(19,4 \%)$ e não determinado em 7 (19,4\%); o sexo de criação final foi feminino em $20(55,5 \%)$ e masculino em $16(45,5 \%)$. Foram realizadas 6 mudanças de masculino para feminino, 7 definições para feminino e nenhuma mudança ou definição para masculino (tabela 1).

O tamanho do falo foi menor ou igual a $-2,5$ DP em 23 casos (63,9\%), entre -2,5 e -1 DP em 9 casos $(25 \%)$ e maior ou igual a -1 DP em 4 casos $(11,1 \%)$ (tabela 1). Dentre os quatro pacientes com falo normal, 3 foram criados no sexo masculino; o mesmo ocorreu com 5 dos 9 casos com falo entre -2,5 e - 1 DP, e apenas 8 dos 23 com falo menor ou igual a $-2,5$ DP (tabela 2). Não se observou, porém, diferença significativa entre o tamanho do falo e o sexo de criação final $\left(\chi^{2}=2,18,2 \mathrm{GL}, \mathrm{p}=0,24\right)$ (tabela 2$)$.

Havia abertura uretral balânica em 4 casos $(11,1 \%)$, peniana em $2(5,5 \%)$, penoescrotal em 5 (13,8 \%) e perineal em $25(69,4 \%)$ (tabela 1). Chama a atenção o fato de que nos 11 pacientes em que a uretra não era perineal a opção foi para sexo masculino.

O cariótipo mais freqüente foi o 46,XX $(47,2 \%)$, seguido por mosaicismos ou quimerismos apresentando linhagem contendo cromossomo $\mathrm{Y}$ (27,8\%), e pelo cariótipo 46,XY com ou sem aberração estrutural de Y (25\%). Dentre os 10 casos de mosaicismo ou quimerismo, três foram 46,XX/46,XY e três foram 45,X/46,XY. O SRY foi negativo em todos os pacientes com cariótipo homogêneo 46,XX (tabela 1 ). Os casos com cariótipo 46,XY (tabela 1 - casos $9,12,27,28,32,35)$ foram submetidos ao seqüenciamento do gene $S R \Upsilon$ na porção do quadro de leitura HMG, com resultado normal.

Observou-se que 10 dos 17 pacientes $(58,8 \%)$ com cariótipo 46,XX e 5 dos $7(71,4 \%)$ com cariótipo $46, \mathrm{XY}$ foram criados no sexo feminino. Dentre os 10 pacientes com mosaicismo ou quimerismo, 60\% foi criado no sexo masculino (tabela 1). Não se observou diferença estatística entre o tipo de cariótipo e o sexo de criação final $\left(\chi^{2}=1,51,2 \mathrm{GL}, \mathrm{p}=0,47\right)$.

Em apenas 5 casos não foi feita a dosagem sérica da testosterona total. Nos demais 31, o teste de estímulo com gonadotrofina coriônica humana foi realizado em 27; destes, 11 apresentaram resposta acima de $150 \mathrm{ng} / \mathrm{dL}, 8$ entre 100 e $150 \mathrm{ng} / \mathrm{dL}$ e 8 abaixo de $100 \mathrm{ng} / \mathrm{dL}$. Nos 4 que não realizaram o teste, a testosterona basal foi maior que $150 \mathrm{ng} / \mathrm{dL}$ em 3 e abaixo de 100 ng/dL em 1 (tabela 3). Não se observaram diferenças significativas entre os níveis de testosterona total e o sexo de criação final $\left(\chi^{2}=1,27,3 \mathrm{GL}, \mathrm{p}=0,74\right)$ (tabela 4 ).

Nos 36 pacientes, foram encontradas 70 gônadas (nos casos 30 e 31 , a gônada direita não foi encontrada); o ovotéstis foi o achado mais freqüente $(33,47 \%)$, seguido de ovário $(19,27 \%)$ e testículo $(17,24 \%)$ (tabela 3$)$. Com relação à lateralidade, observou-se a existência de tecido testicular 
Tabela 1. Idade na primeira consulta, cariótipo, tamanho do falo, abertura uretral, sexo inicial e de criação em 36 casos de HV.

\begin{tabular}{|c|c|c|c|c|c|c|}
\hline \multirow[t]{2}{*}{ Caso } & \multirow[t]{2}{*}{ Idade } & \multirow[t]{2}{*}{ Cariótipo (SRY) } & \multirow[t]{2}{*}{ Falo em cm (DP) } & \multirow[t]{2}{*}{ Uretra } & \multicolumn{2}{|c|}{ Sexo criação } \\
\hline & & & & & Inicial & Final \\
\hline 1 & $198 m$ & 46,XX (SRY -) & $2(<-2,5 \mathrm{DP})$ & PER & $\mathrm{F}$ & $\mathrm{F}$ \\
\hline 2 & $17 a 1 m$ & $46, X X(S R Y-)$ & $3(<-2,5 \mathrm{DP})$ & PER & $M$ & M \\
\hline 3 & $6 m$ & $45, X / 46, X Y / 46, X, \operatorname{inv}(Y)$ & $1(<-2,5 \mathrm{DP})$ & PER & $M$ & $\mathrm{~F}$ \\
\hline 4 & $1 a 2 m$ & $46, X X(S R Y-)$ & $1,5(<-2,5 \mathrm{DP})$ & PER & $M$ & M \\
\hline 5 & $5 a 8 m$ & $45, X / 46, X Y$ & $3(<-2,5 \mathrm{DP})$ & PEN & $\mathrm{M}$ & $\mathrm{M}$ \\
\hline 6 & $10 \mathrm{a} 8 \mathrm{~m}$ & $45, X / 46, X X / 47, X X Y$ & $3(<-2,5 \mathrm{DP})$ & PER & $M$ & $\mathrm{M}$ \\
\hline 7 & $7 m$ & $46, X X(S R Y-)$ & $1(<-2,5 \mathrm{DP})$ & PER & $\mathrm{F}$ & $\mathrm{F}$ \\
\hline 8 & $1 \mathrm{a} 10 \mathrm{~m}$ & $46, X X(S R Y-)$ & $3(-2$ DP) & PER & $M$ & $\mathrm{~F}$ \\
\hline 9 & $11 d$ & $46, X Y$ (SRY normal) & $2(<-2,5$ DP $)$ & PER & 1 & $\mathrm{~F}$ \\
\hline 10 & $2 a$ & $46, X X(S R Y-)$ & $1(<-2,5 \mathrm{DP})$ & PER & I & $\mathrm{F}$ \\
\hline 11 & $24 d$ & $45, X / 46, X Y$ & $2,5(-2 \mathrm{DP})$ & PER & I & $\mathrm{F}$ \\
\hline 12 & $11 d$ & $46, X Y$ (SRY normal) & $2,5(-2 \mathrm{DP})$ & PER & I & $\mathrm{F}$ \\
\hline 13 & $6 a 4 m$ & $46, X X(S R Y-)$ & $2,5(<-2,5 \mathrm{DP})$ & PER & $\mathrm{F}$ & $\mathrm{F}$ \\
\hline 14 & $4 a 5 m$ & $46, X X(S R Y-)$ & $2(<-2,5 \mathrm{DP})$ & BAL & $M$ & $M$ \\
\hline 15 & $4 \mathrm{~m}$ & $46, X, r(Y)$ & $2(<-2,5 \mathrm{DP})$ & PER & $M$ & $\mathrm{~F}$ \\
\hline 16 & $1 \mathrm{a} 11 \mathrm{~m}$ & $45, X / 46, X, r(Y)$ & $2,5(<-2,5 \mathrm{DP})$ & PER & $M$ & $M$ \\
\hline 17 & la3m & $46, X X(S R Y-)$ & $2,5(<-2,5 \mathrm{DP})$ & PER & 1 & $\mathrm{~F}$ \\
\hline 18 & $2 m$ & $46, X X(S R Y-)$ & $4(0 \mathrm{DP})$ & BAL & $M$ & $M$ \\
\hline 19 & $10 d$ & $46, X X(S R Y-)$ & $3(-1 \mathrm{DP})$ & PER & I & $\mathrm{F}$ \\
\hline 20 & $6 m$ & $46, X X / 47, X X Y$ & $3(-1,5$ DP $)$ & PS & $M$ & $M$ \\
\hline 21 & $12 d$ & $46, X X(S R Y-)$ & $2(<-2,5 \mathrm{DP})$ & PER & $\mathrm{F}$ & $\mathrm{F}$ \\
\hline 22 & $12 a$ & $46, X X(S R Y-)$ & $5(-1$ DP) & BAL & $M$ & $M$ \\
\hline 23 & $1 \mathrm{a} 5 \mathrm{~m}$ & $46, X Y$ & 4 (O DP) & BAL & $M$ & $\mathrm{M}$ \\
\hline 24 & $3 m$ & 46,XX (SRY -) & $2(<-2,5 \mathrm{DP})$ & PER & I & $\mathrm{F}$ \\
\hline 25 & $8 a 4 m$ & $46, X X(S R Y-)$ & $2,5(<-2,5 D P)$ & PER & $\mathrm{F}$ & $\mathrm{F}$ \\
\hline 26 & $20 d$ & $46, X X / 46, X Y$ & $2(<-2,5 D P)$ & PER & $\mathrm{F}$ & $\mathrm{F}$ \\
\hline 27 & $6 a 4 m$ & $46, X Y$ (SRY normal) & $4(-1,5$ DP $)$ & PS & $M$ & $M$ \\
\hline 28 & $1 a 7 m$ & $46, X Y$ (SRY normal) & $2(<-2,5 \mathrm{DP})$ & PER & $M$ & $\mathrm{~F}$ \\
\hline 29 & $10 a 8 m$ & $45, X / 47, X Y Y$ & $2(<-2,5 \mathrm{DP})$ & PER & $\mathrm{F}$ & $\mathrm{F}$ \\
\hline 30 & 7a9m & $46, X X$ (SRY-) & $3(<-2,5 \mathrm{DP})$ & PER & $M$ & $M$ \\
\hline 31 & $12 \mathrm{alm}$ & $46, X X / 46, X Y$ & $4(-2 \mathrm{DP})$ & PS & $M$ & $M$ \\
\hline 32 & $1 \mathrm{lal} 1 \mathrm{~m}$ & $46, X Y$ (SRY normal) & 3 (-2 DP) & PER & $M$ & $\mathrm{~F}$ \\
\hline 33 & $19 a 11 \mathrm{~m}$ & $46, X X / 46, X Y$ & $4(<-2,5 \mathrm{DP})$ & PS & $M$ & $M$ \\
\hline 34 & la9m & $46, X, \operatorname{del}(Y q)$ & $3(-2 \mathrm{DP})$ & PS & $M$ & $M$ \\
\hline 35 & $3 a$ & $46, X Y$ (SRY normal) & $3(-2,5 \mathrm{DP})$ & PER & $M$ & $\mathrm{~F}$ \\
\hline 36 & $2 m$ & $46, X X(S R Y-)$ & $3(-2 D P)$ & PEN & $M$ & $M$ \\
\hline
\end{tabular}

$\mathrm{a}=$ anos; $\mathrm{m}=$ meses; $\mathrm{M}=$ masculino; $\mathrm{F}=$ feminino; $\mathrm{l}=$ indeterminado;

$\mathrm{BAL}=$ balânica; $\mathrm{PEN}=$ peniana; $\mathrm{PS}=$ penoescrotal; $\mathrm{PER}=$ perineal

Tabela 2. Opção de sexo de criação em relação ao tamanho do falo em 36 casos de HV.

\begin{tabular}{lccc}
\hline Tamanho do falo; & $\mathbf{N}$ & Sexo masculino & Sexo feminino \\
\hline >-1 DP & 4 & 3 & 1 \\
entre -1 e -2,5 DP & 9 & 5 & 4 \\
$\leq-2,5$ DP & 23 & 8 & 15 \\
\hline
\end{tabular}

(testículo ou ovotéstis) em 22 das 34 gônadas $(64,7 \%)$ situadas no lado direito, enquanto que dentre as 36 situadas no lado esquerdo, $30(83,3 \%)$ continham tecido testicular (tabela 5 ).

Apenas um paciente (caso 27) apresentou gonadoblastoma $(2,7 \%)$; este estava presente em ambas as gônadas, um testículo e um ovário. Nos casos $1,7,8,10$ e 13, que foram criados no sexo feminino, foi possível remover somente a porção testicular do ovotéstis e, conseqüentemente, manter a porção ovariana.

A associação de tecido gonadal mais encontrada 
Tabela 3. Gônadas e valores de testosterona total basal e após estímulo com gonadotrofina coriônica humana em 36 casos de HV.

\begin{tabular}{|c|c|c|c|c|}
\hline Caso & $\begin{array}{l}\text { Gônada } \\
\text { Direita }\end{array}$ & $\begin{array}{l}\text { Gônada } \\
\text { Esquerda }\end{array}$ & $\begin{array}{c}\text { Teststerona } \\
\text { basal }\end{array}$ & $\begin{array}{c}\text { Testosterona } \\
\text { após hCG }\end{array}$ \\
\hline 1 & Ovário & Ovotéstis & 10,5 & 158 \\
\hline 2 & Ovotéstis & Ovário & NR & NR \\
\hline 3 & Ovotéstis & Ovotéstis & 22 & 146 \\
\hline 4 & Ovotéstis & Ovotéstis & 123 & 595 \\
\hline 5 & Ovário & Testículo & NR & NR \\
\hline 6 & Ovário & Ovotéstis & NR & NR \\
\hline 7 & Ovotéstis & Ovotéstis & 22 & 625 \\
\hline 8 & Ovotéstis & Ovotéstis & NR & NR \\
\hline 9 & Testículo & Ovotéstis & 115 & 195 \\
\hline 10 & Ovário & Ovotéstis & 8 & 223 \\
\hline 11 & Disgenética & Ovotéstis & NR & NR \\
\hline 12 & Ovotéstis & Testículo & 306 & 482 \\
\hline 13 & Ovotéstis & Ovotéstis & 19 & 88 \\
\hline 14 & Ovotéstis & Ovotéstis & 8 & 103 \\
\hline 15 & Ovário & Testículo & 13 & 132 \\
\hline 16 & Testículo & Ovotéstis & 4 & 353 \\
\hline 17 & Ovário & Ovotéstis & 12 & 114 \\
\hline 18 & Ovotéstis & Ovotéstis & 15 & 470 \\
\hline 19 & Ovotéstis & Ovotéstis & 85 & NR \\
\hline 20 & Testículo & Ovário & NR & 101 \\
\hline 21 & Ovotéstis & Ovário & 10 & 147 \\
\hline 22 & Ovotéstis & Testículo & 250 & NR \\
\hline 23 & Ovotéstis & Testículo & 10 & 185 \\
\hline 24 & Ovário & Testículo & 393 & 493 \\
\hline 25 & Ovário & Ovotéstis & 7 & 239 \\
\hline 26 & Ovário & Ovotéstis & 10 & 115 \\
\hline 27 & Ovário (GB) & Testículo (GB) & 10 & 10 \\
\hline 28 & Testículo & Ovário & 11 & 38 \\
\hline 29 & Testículo & Ovário & 12 & 15 \\
\hline 30 & Ausente & Ovotéstis & 8 & 44 \\
\hline 31 & Ausente & Ovotéstis & 180 & NR \\
\hline 32 & Testículo & Ovário & 10,5 & 68 \\
\hline 33 & Testículo & Ovário & 456 & NR \\
\hline 34 & Testículo & Ovário & 14 & 70 \\
\hline 35 & Ovário & Testículo & 26 & 98 \\
\hline 36 & Testículo & Ovotéstis & 34 & 104 \\
\hline
\end{tabular}

$\mathrm{GB}=$ gonadoblastoma; $\mathrm{TT}=$ testosterona total;

$\mathrm{hCG}=$ gonadotrofina coriônica humana; $\mathrm{NR}=$ não realizada

Tabela 4. Valores séricos da testosterona total em relação ao tipo de associação de tecido gonadal em 33 casos de HV.

\begin{tabular}{|c|c|c|c|c|c|}
\hline & OT + OT & OT + OV & OT + TT & $O V+\pi$ & Total \\
\hline $\begin{array}{l}\text { Test total } \\
\geq 150 \mathrm{ng} / \mathrm{dL} \\
\text { Test total entre }\end{array}$ & 3 & 3 & 5 & 2 & 13 \\
\hline $\begin{array}{l}100 \text { e } 150 \mathrm{ng} / \mathrm{dL} \\
\text { Test total }\end{array}$ & 2 & 3 & 1 & 2 & 8 \\
\hline $\begin{array}{l}\leq 100 \mathrm{ng} / \mathrm{dL} \\
\text { Test total }\end{array}$ & 2 & 0 & 0 & 6 & 8 \\
\hline não realizada & 1 & 2 & 0 & 1 & 4 \\
\hline Total & 8 & 8 & 6 & 11 & $33^{*}$ \\
\hline
\end{tabular}

Tabela 5. Tipo de tecido gonadal e lateralidade observados em 36 casos de HV.

\begin{tabular}{lcccccc}
\hline Lateralidade & Ovotéstis & Ovário & Testículo & Disgenética & Ausente & Total \\
\hline Direita & 13 & 11 & 9 & 1 & 2 & 36 \\
Esquerda & 20 & 8 & 8 & 0 & 0 & 36 \\
Total & 33 & 19 & 17 & 1 & 2 & 72 \\
\hline
\end{tabular}


Tabela 6. Associação de tecido gonadal e cariótipo em 36 casos de HV.

\begin{tabular}{lcccccc}
\hline & $\mathbf{4 6 , X X}$ & $\mathbf{4 6 , X Y}$ & $\mathbf{4 6 , X , r ( Y )}$ & $\mathbf{4 6 , X , d e l}(\mathbf{Y q})$ & Mosaicismo & Total \\
\hline OV + TT & 1 & 4 & 1 & 1 & 4 & $11(30,5 \%)$ \\
OT + OV & 6 & 0 & 0 & 0 & 2 & $8(22,2 \%)$ \\
OT + OT & 7 & 0 & 0 & 0 & 1 & $8(22,2 \%)$ \\
OT + TT & 2 & 3 & 0 & 0 & 1 & $6(16,6 \%)$ \\
DG + OT & 0 & 0 & 0 & 0 & 1 & $1(2,7 \%)$ \\
AUS + OT & 1 & 0 & 0 & 0 & 1 & $2(5,5 \%)$ \\
Total & 17 & 7 & 1 & 1 & 10 & $36(100 \%)$ \\
\hline
\end{tabular}

$\mathrm{OT}=$ ovotéstis; $\mathrm{OV}=$ ovário; $\mathrm{TT}=$ testículo; $\mathrm{DG}=$ disgenética; $\mathrm{AUS}=$ ausente

foi ovário e testículo (30,5\%), seguida por ovotéstis e ovário $(22,2 \%)$, ovotéstis bilaterais $(22,2 \%)$ e ovotéstis e testículo $(16,6 \%)$ (tabela 5$)$. Não se observou diferença estatística entre os grupos de associação de tecido gonadal e o sexo de criação final $\left(\chi^{2}=5,89,5 \mathrm{GL}\right.$, $\mathrm{p}=0,32)$. No entanto, houve diferença significativa entre esses mesmos grupos em relação ao cariótipo $\left(\chi^{2}=21,74,10 \mathrm{GL}, \mathrm{p}=0,02\right)$, sendo mais freqüentes as associações ovotéstis com ovotéstis e ovotéstis com ovário em cariótipos $46, \mathrm{XX}$, e ovotéstis com testículo e ovário com testículo em cariótipos 46,XY (tabela 6).

Dos 17 testículos encontrados nos 36 pacientes (11 associados a ovotéstis e 6 a ovário), apenas 3 eram de indivíduos com cariótipo 46,XX; em todos os demais havia cromossomo Y no cariótipo (tabela 6).

Dos seis casos de associação ovotéstis e testículo, cinco apresentaram testosterona acima de $150 \mathrm{nd} / \mathrm{dL}$, enquanto que nos $1 \mathrm{l}$ casos de associação ovário e testículo, 6 apresentaram testosterona abaixo de 100ng/dL. Nas associações ovotéstis com ovotéstis e ovotéstis com testículo observou-se uma distribuição homogênea dos valores de testosterona total (tabela 4). Não se observou diferença significativa entre os grupos de associação de tecido gonadal em relação aos níveis de testosterona total $\left(\chi^{2}=\right.$ $21,86,15 \mathrm{GL}, \mathrm{p}=0,11$ ).

\section{DISCUSSĀO}

O HV continua a ser uma condição clínica que desafia a compreensão de clínicos e de pesquisadores na área das anomalias da diferenciação sexual $(7,14)$.

A grande maioria dos pacientes portadores de HV é encaminhado aos serviços especializados devido à ambigüidade genital. No entanto, o HV pode coexistir com genitálias externas normais, não ambíguas; esses casos acabam sendo diagnosticados devido ao achado casual de tecido ovariano e testicular $(2,4)$. Chama a atenção, sob este aspecto, o caso descrito na literatura de uma senhora de 52 anos de idade que, ao ter seu nono filho, foi submetida a histerectomia e salpingo-ooforectomia bilateral devido a um cistadenoma mucinoso no ovário direito. A gônada esquerda foi explorada e, para surpresa da equipe médica, consistia de tecido ovariano e testicular (ovotéstis), configurando um HV (15). Há ainda o relato de um caso de HV criado no sexo masculino, com genitália externa normal e fertilidade comprovada, fato esse bastante incomum no HV (16). Na casuística apresentada neste estudo, em apenas 1 dos 36 casos não foi observada genitália ambígua; além disso, um outro paciente não havia sido encaminhado ao serviço médico por ambigüidade genital.

A procura tardia por serviços especializados caracterizou este estudo, sendo acompanhada de definição prévia do sexo na maioria dos casos. Estes dois fatores podem ter impossibilitado uma maior discussão sobre a definição do sexo de criação; mesmo assim, ainda houve um predomínio significativo de casos criados no sexo feminino, como recomenda a literatura $(1,2)$. No entanto, Niekerk e Retief (4) observaram um predomínio de definição para o sexo masculino $(60 \%)$ em relação ao feminino.

Um dado clínico que pode ser utilizado na escolha do sexo de criação é o tamanho do falo $(1,7)$. Neste estudo não foi encontrada diferença estatística entre o tamanho do falo e o sexo de criação final. Já o posicionamento do meato uretral, também considerado nesta decisão, foi levado em conta em nossos pacientes, como se pode observar na tabela l: a grande maioria $(25 / 36)$ apresentava o orifício uretral em localização perineal, sendo feita a opção para sexo feminino em 20 dos 25 casos (80\%). Quando o posicionamento do meato uretral não era perineal $(11 / 36)$, a opção de sexo de criação foi sempre masculina.

$\mathrm{O}$ cariótipo mais freqüentemente encontrado foi o 46,XX, seguido por mosaicismos ou quimerismos e, em menor escala, pelo cariótipo 46,XY, em concordância com dados da literatura $(2,4,5,8)$. Apesar do cariótipo mais freqüente ser o 46,XX com $S R \Upsilon$ ausente, o desenvolvimento de tecido testicular e ovariano exige que sejam aventados outros mecanis- 
mos de controle na progressão de uma gônada indiferenciada a testículo, além da idéia inicial de que bastaria o fator de determinação sexual (TDF), presentemente representado pelo $S R \Upsilon$, para que a gônada diferencie-se em testículo $(1,7,17)$.

A questão mais intrigante refere-se a como, num mesmo indivíduo, parte da gônada bipotencial diferencia-se em testículo e parte em ovário. A tentativa de encontrar alterações no $S R \Upsilon$ nos casos em que este fator de transcrição está presente não tem sido produtiva. Em dois dos casos deste estudo com cariótipo $46, \mathrm{XY}$ o $S R \Upsilon$ foi seqüenciado e mostrou-se normal.

A maior parte dos HV com cariótipo 46,XX são $S R \Upsilon$-negativos em sangue periférico ou fibroblastos $(5,6,8,11,18)$. No entanto, quando a investigação do SR $\Upsilon$ é feita no tecido gonadal, por imunohistoquímica ou por FISH, alguns autores relataram resultados positivos $(10,19,20)$ e outros não $(8)$. Nesta casuística, os 6 casos de HV 46,XY apresentaram seqüenciamento normal do gene SRY. No entanto, estudos de biologia molecular nos ovotéstis deste tipo de paciente mostraram a presença de mosaicismo com $S R \Upsilon$ normal e com mutação, sugerindo que uma mutação pós-zigótica no $S R \Upsilon$ pode causar o surgimento de ovotéstis (2l).

A escolha do sexo de criação também não foi baseada no cariótipo, de modo semelhante ao observado por Krob e cols. (2) e diferente do encontrado por Niekerk e Retief (2), que verificaram associação entre a definição para sexo feminino e a ausência de $\mathrm{Y}$ no cariótipo.

Os valores de testosterona total sérica observados neste estudo variaram amplamente e não se correlacionaram com cariótipo, tipo de associação de tecido gonadal ou sexo de criação.

A gônada mais freqüentemente encontrada nos 36 casos deste estudo foi o ovotéstis (47\%), seguida do ovário $(27 \%)$, como mostrado na literatura $(2,4)$. O achado de testículo nesta casuística foi de $24 \%$, maior que a freqüência encontrada por Krob e cols. (2). Um outro dado interessante diz respeito à lateralidade da gônada que contém tecido testicular: alguns autores têm afirmado que tais gônadas concentram-se mais do lado direito, que apresenta um crescimento mais rápido, e associam a maior velocidade de divisão celular ao desenvolvimento testicular $(2,4,6,21)$. Neste estudo, porém, foi mais freqüente o achado de gônadas contendo tecido testicular do lado esquerdo.

A associação de gônadas mais comum foi ovário e testículo, concordando com os dados de van Niekerk e Retief (4) em ampla revisão de 409 casos publicada em 1981. Já na revisão de 283 casos feita por Krob e cols. (2) em 1994 a associação mais comum foi ovotéstis e ovário.
Como o tecido ovariano, diferentemente do tecido testicular, é, em geral, funcionante, deve-se tentar preservar a porção ovariana do ovotéstis nos casos que serão criados no sexo feminino; esse procedimento, recomendado por outros autores $(2,19)$, foi realizado em cinco casos deste estudo. Com isso, tenta-se permitir a puberdade espontânea e, eventualmente, a fertilidade. Como tais pacientes, em sua maioria, apresentam cariótipo 46,XX, o risco de malignização gonadal é baixo, cerca de $3 \%$. Quando, no entanto, houver a presença de cromossomo $\mathrm{Y}$ e o testículo for mantido, este risco pode subir a $25 \%$, já que nos $\mathrm{HV}$, em geral, o testículo é disgenético. Quando o paciente apresenta mosaicismo ou quimerismo cromossômicos, curiosamente, o risco de neoplasia é muito baixo e alguns autores sugerem, nesses casos, a manutenção da gônada compatível com o sexo de criação, mesmo que seja um testículo e que haja linhagem com cromossomo Y $(2,22)$.

Apesar de pouco freqüente no contexto das anomalias da diferenciação sexual, o HV é sempre um desafio em termos de compreensão fisiopatológica e da própria opção do gênero de criação. Qualquer cariótipo pode estar presente e a variedade de apresentações clínicas é bastante grande. Na maioria dos casos, tem-se privilegiado a opção pelo sexo feminino, pelas possibilidades de preservação do tecido ovariano, usualmente funcionante e com possibilidades de fertilidade.

\section{CONCLUSŌES}

Apesar da maioria dos HV ter apresentado genitália ambígua, deve-se lembrar que a genitália externa pode ser normal.

Uma boa parte dos HV chegou tarde aos Serviços de Endocrinologia Pediátrica, o que dificultou a tomada de decisão quanto ao sexo de criação.

O cariótipo mais freqüente nos HV foi o $46, \mathrm{XX}$ e todos estes apresentaram SR $\Upsilon$ negativo em DNA genômico extraído de leucócitos periféricos.

A decisão sobre o sexo de criação privilegiou a opção feminina e esta escolha não se relacionou ao cariótipo, ao tamanho do falo, ou aos valores da testosterona sérica.

O posicionamento do meato uretral, se perineal ou não, influenciou a opção de sexo de criação, já que dentre os 25 pacientes que apresentavam uretra perineal $20(80 \%)$ foram criados no sexo feminino, enquanto que em todos os 11 pacientes em que a uretra não era perineal (balânica, peniana ou peno-escrotal) o sexo de criação foi definido como masculino. 
A gônada mais freqüente foi o ovotéstis e a associação mais comum foi ovário e testículo.

Observou-se associação entre cariótipo 46,XX e presença de ovotéstis com ovotéstis ou ovotéstis com ovário, e cariótipo 46,XY com ovotéstis com testículo e ovário com testículo.

\section{AGRADECIMENTOS}

À Profa. Célia Koifmann, do Departamento de Genética Médica da USP, responsável pelos cariótipos dos pacientes acompanhados no Instituto da Criança, e ao Laboratório de Citogenética do Departamento de Genética Médica da UNICAMP pelos cariótipos dos pacientes do GIEDDS. Aos Profs. Carlos Alberto Moreira-Filho, Instituto de Ciências Biológicas, e Berenice Bilharino de Mendonça, Sorahia Domenice e seu grupo, Faculdade de Medicina da USP, pela pesquisa e seqüenciamento do SRY nos pacientes do Instituto da Criança, e ao Laboratório de Genética Médica do Centro de Biologia Molecular e Engenharia Genética da UNICAMP pela pesquisa do SRY nos pacientes do GIEDDS.

\section{REFERÊNCIAS}

1. Guerra-Júnior G. Hermafroditismo Verdadeiro. In: Maciet Guerra AT, Guerra-Júnior G, editores. Menino ou menina? Os distúrbios da diferenciação do sexo. São Paulo:Editora Manole Ltda; 2002.p.53-7.

2. Krob G, Braun A, Kuhnle U. True hermaphroditism: geographical distribution, clinical findings, chromosomes and gonadal histology. Eur J Pediatr 1994;153:2-10.

3. Wiersma R. True hermaphroditism in southern Africa: the clinical picture. Pediatr Surg Int 2004;20:363-8.

4. van Niekerk WA, Retief AE. The gonads of human true hermaphrodites. Hum Genet 1981;58:117-22.

5. Damiani D, Fellous M, McElreavey K, Barbaux S, Barreto ESA, Dichtchekenian V, et al. True hermaphroditism: clinical aspects and molecular sudies in 16 cases. Eur J Endocrinol 1997;136:201-4.

6. Guerra-Júnior G, Mello MP, Assumpção JG, Morcillo AM, Marini SHVL, Baptista MTM, et al. True hermaphrodites in southeastern region of Brazil: a different cytogenetic and gonadal profile. J Pediatr Endocrinol Metab 1998; 11:519-24.

7. Damiani D. O enigma da determinação gonadal. In: Setian $\mathrm{N}$, editora. Endocrinologia Pediátrica. Aspectos físicos e metabólicos do recém-nascido ao adolescente. São Paulo:Editora Sarvier; 2003.p.433-7.

8. Domenice S, Nishi MY, Billerbeck AEC, Carvalho FM, Frade EMC, Latronico AC, et al. Molecular analysis of SRY gene in Brazilian 46,XX sex reversed patients: absence of SRY sequences in gonadal tissue. Med Sci Monit 2001;7:238-41.

9. Torres L, López M, Méndez JP, Canto P, Cervantes A, Alfaro G, et al. Molecular analysis in true hermaphrodites with different karyotypes and similar phenotypes. Am J Med Genet 1996;63:348-55

10. Queipo G, Zenteno JC, Peña R, Nieto K, Radillo A, Dorantes LM, et al. Molecular analysis in true hermaphroditism: demonstration of low-level hidden mosaicism for Y-derived sequences in 46,XX cases. Hum Genet 2002;111:278-83.

11. Braun A, Kammerer S, Cleve H, Lohrs U, Schwarz HP, Kuhnle U. True hermaphroditism in a $46, X Y$ individual, caused by a postzygotic somatic point mutation in the male gonadal sexdetermining locus (SRY): molecular genetics and histological findings in a sporadic case. Am J Hum Genet 1993;52:578-85.

12. Barreto ESA, Damiani D, Dichtchekenian V, Setian N. Hermafroditismo Verdadeiro: aspectos clínicos de 14 casos. Arq Bras Endocrinol Metab 1996;40:193-7.

13. Lee PA, Mazur T, Danish R, Amrhein J, Blizzard RM, Money J, et al. Micropenis. I - Criteria, etiologies, and classification. Johns Hopk Med J 1980;146:156-63.

14. MacLaughlin DT, Donahoe PK. Mechanisms of disease: sex determination and differentiation. N Engl J Med 2004;350:36778.

15. Tiltman AJ, Sweerts M. Multiparty in a covert true hermaphrodite. Obstet Gynecol 1982;60:752-4.

16. Parvin SC. Ovulation in a cytonenetically proved phenotypically male fertile hermaphrodite. Br J Surg 1982;69:279-80.

17. Sinclair AH, Berta P, Palmer MS, Hawkins JR, Griffiths BL, Smith MJ, et al. A gene from the human sex-determining region encodes a protein with homology to a conserved DNA-binding motif. Nature 1990;346:240-4

18. Assumpção JG, Maciel-Guerra AT, Guerra-Junior G, Scolfaro MR, Mello MP. Two novel SRY mutations: the HMGbox N65H associated with $46, X Y$ pure gonadal dysgenesis and the familial non-HMGbox R30l associated with different phenotypes. J Mol Med 2002;80:782-90.

19. Hadjiahanasiou CG, Brauner R, Lortat-Jacob S, Nivolt S, Jaubert F, Fellous M, et al. True hermaphroditism: genetic variants and clinical management. J Pediatr 1994; 125:738-44.

20. Ortenberg J, Oddoux C, Craver R, McElreavey K, Salas-Cortes L, Guillen-Navarro E, et al. SRY gene expression in the ovotestes of XX true hermaphrodites. J Urol 2002;167:1828-31.

21. Mittwoch U. Males, females and hermaphrodites. Ann Hum Genet 1985;50:103-21.

22. Kuhnle U, Krob G, Maier E. True hermaphroditism: presentation, management, outcome. The Endocrinologist 2003;13:214-8.

\section{Endereço para correspondência:}

\section{Durval Damiani}

Rua Bela Cintra 2117, apto 9

01415-002 São Paulo, SP

E-mail: durvald@iconet.com.br 